\title{
New Approaches to Neuroprotection in Infant Heart Surgery
}

\author{
ERIN L. ALBERS, DAVID P. BICHELL, AND BETHANN MCLAUGHLIN \\ Departments of Pediatrics [E.L.A.], Cardiac Surgery [D.P.B.], Neurology [B.M.], Clinical Pharmacology [E.L.A.], and Pharmacology \\ [B.M.], Vanderbilt University School of Medicine, Nashville, Tennessee 37323
}

\begin{abstract}
Advances in surgical techniques and perioperative management have led to dramatic improvements in outcomes for children with complex congenital heart disease (CHD). As the number of survivors continues to grow, clinicians are becoming increasingly aware that adverse neurodevelopmental outcomes after surgical repair of CHD represent a significant cause of morbidity, with widespread neuropsychologic deficits in as many as $50 \%$ of these children by the time they reach school age. Modifications of intraoperative management have yet to measurably impact long-term neurologic outcomes. However, exciting advances in our understanding of the underlying mechanisms of cellular injury and of the events that mediate endogenous cellular protection have provided a variety of new potential targets for the assessment, prevention, and treatment of neurologic injury in patients with CHD. In this review, we will discuss the unique challenges to developing neuroprotective strategies in children with CHD and consider how multisystem approaches to neuroprotection, such as ischemic preconditioning, will be the focus of ongoing efforts to develop new diagnostic tools and therapies. Although significant challenges remain, tremendous opportunity exists for the development of diagnostic and therapeutic interventions that can serve to limit neurologic injury and ultimately improve outcomes for infants and children with CHD. (Pediatr Res 68: 1-9, 2010)
\end{abstract}

$\mathrm{A}$ dvances in surgical techniques and perioperative management have led to dramatic improvements in survival outcomes for children with complex congenital heart disease (CHD). Indeed, children born with lesions that were fatal as recently as $30 \mathrm{y}$ ago are now surviving into adolescence and adulthood (1). With a growing population of survivors, clinicians are becoming increasingly aware that patients who have undergone life-saving open-heart surgery as infants and young children are facing significant neurocognitive challenges as they develop and mature. Widespread neurodevelopmental deficits can be identified in as many as 50\% of these children by the time they reach school age (2). These delays manifest in attentional and academic problems, which ultimately result in significant social and economic challenges to patients and families.

Received December 2, 2009; accepted March 12, 2010.

Correspondence: BethAnn McLaughlin, Ph.D., Department of Pharmacology, Vanderbilt University School of Medicine, 465 21st Avenue South, MRB III Room 8110A, Nashville, TN 37232-8548; e-mail: bethann.mclaughlin@vanderbilt.edu

Supported by NIH Grants NS050396 (B.M.), GM07569-32 (E.A.), and P30HD15052.
The mechanisms contributing to CNS injury in patients with CHD are complex and multifactorial, occurring throughout prenatal and perinatal life. Insults to the developing brain may occur in utero (as a result of coincident structural brain malformation and/or disordered fetal circulation), in the immediate postnatal period while awaiting surgical intervention (related to cyanosis, perturbed cerebrovascular autoregulation, or hypoxic-ischemic injury due to ongoing hemodynamic instability), intraoperatively (as a consequence of cardiopulmonary bypass, hypothermia, hemodilution, or cerebral embolic events), and during the postoperative period (because of low cardiac output syndrome, seizures, systemic infection, or other complications) (3-5). Long-term neurologic functioning in these children is also impacted by the presence of underlying genetic syndromes, the influence of social and environmental factors, and the cardiac lesion itself, which necessarily dictates the timing and nature of surgical intervention. There is a growing body of literature that suggests that patients requiring surgery in the first few weeks of life have a significantly higher incidence of academic difficulties and behavior abnormalities as they reach school-age. Patients that require several stages of palliative repair in early childhood may be particularly vulnerable to brain injury and subsequent disability (Figs. 1 and 2) (4,6-11).

Historical approaches to neuroprotection in this population have focused on the most obviously modifiable factors, particularly intraoperative management strategies. However, despite increasing attention to this problem, no consistent improvement in long-term neurodevelopmental outcomes has been achieved in nearly two decades (12). Indeed, it has become clear that alternative approaches to this problem are needed. ${ }^{1}$ New insights into pre- and postoperative risk factors that contribute to adverse neurologic outcomes in children with CHD, along with advances in the understanding of the underlying mechanisms that direct cellular injury and protection in a variety of similar populations, can now serve as a basis on which to formulate new strategies for the diagnosis,

Abbreviations: CHD, congenital heart disease; CPB, cardiopulmonary bypass; HIF, hypoxia inducible factor; HLHS, hypoplastic left heart syndrome; IPC, ischemic preconditioning; LCOS, low cardiac output syndrome; PVL, per ventricular leukomalacia; RIPC, remote ischemic preconditioning 


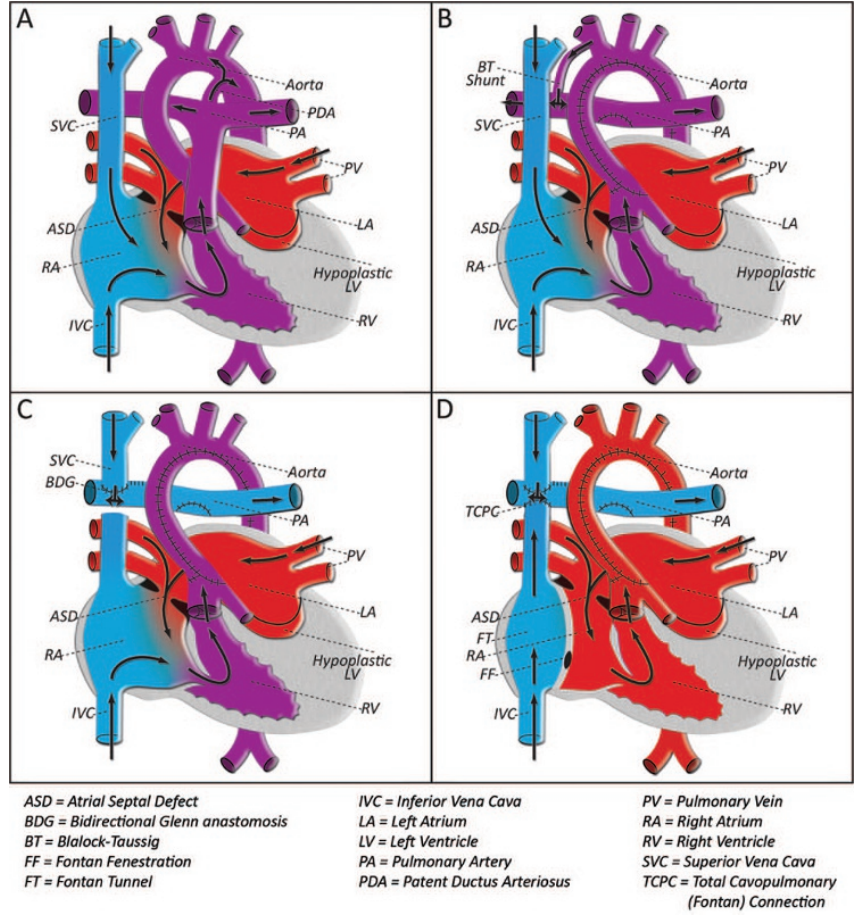

Figure 1. Staged surgical palliation for HLHS; although these interventions have led to improved survival, patients with HLHS remain at risk for adverse neurodevelopmental outcomes. A) HLHS includes a spectrum of defects, which are characterized by the underdevelopment of left heart structures including the mitral valve, left ventricle, and aorta. Decreased cerebral perfusion in utero may contribute to prenatal CNS insult in this lesion. After birth, and programmed closure of the ductus arteriosus, the hypoplastic left ventricle and aorta are unable to maintain the systemic circulation, resulting in decreased coronary and cerebral perfusion, cardiogenic shock, and death if not treated. $B$ ) Stage I palliation, the Norwood operation, is typically performed in the first week of life. This procedure involves reconstruction of the ascending aorta and aortic arch using the native pulmonary artery. Pulmonary blood flow is achieved via a systemic to pulmonary arterial shunt, and the right ventricle bears the workload of both the systemic and pulmonary circulations. This physiology places a volume load on the right ventricle, and with significant risk for complications related to the systemicpulmonary shunt, it is unsuitable for long term palliation. C) Stage II palliation, the bidirectional Glenn anastomosis, is undertaken at the age of 3 to $6 \mathrm{mo}$. Systemic venous blood from the upper body is redirected to the lungs via a superior vena cava to pulmonary artery anastomosis. The timing of this surgery is based on the physiologic reduction in pulmonary vascular resistance that occurs over the first several weeks of life. Glenn physiology reduces the volume load on the single right ventricle, rendering it more stable over time. However, it requires mixing of deoxygenated blood (venous return from the lower body) with the systemic output, resulting in cyanosis at baseline. D) Stage III palliation, the Fontan completion, is performed at the age of 2-4 y and completes the in-series circuit by directing the venous blood from the lower body into the pulmonary circulation. With this total cavopulmonary connection, the right ventricle remains the single pumping chamber to the body, whereas the pulmonary circulation is driven by passive venous flow to the lungs. At this stage, there is no longer mixing of oxygenated and deoxygenated blood, and systemic saturations are normal. Arrows indicate direction of blood flow. Blue indicates deoxygenated blood, red indicates oxygenated blood, purple indicates mixed oxygenated and deoxygenated blood.

treatment, and prevention of neurologic injury in patients with CHD.

\section{Historical Approaches to Neuroprotection in Infant Heart Surgery}

Technical modifications. After the introduction of deep hypothermic circulatory arrest (DHCA) in the 1940s and

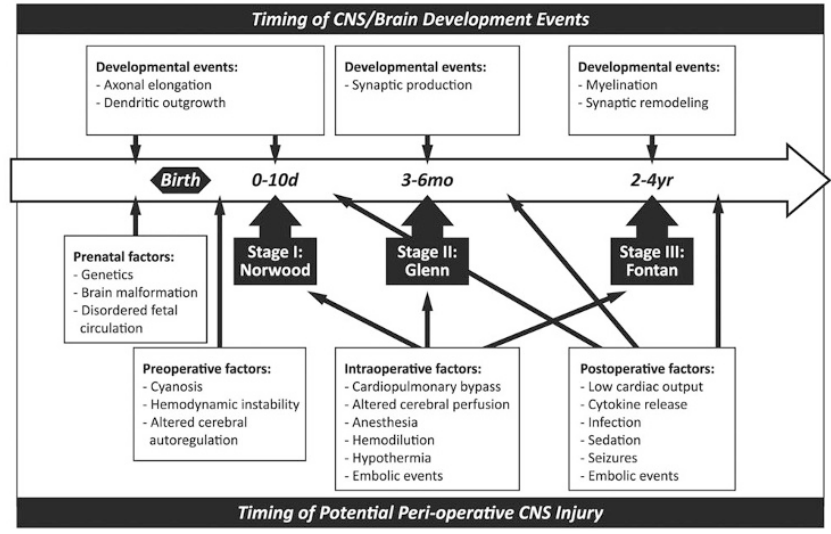

Figure 2. Timeline of potential neurologic injury throughout staged palliation for HLHS in relation to corresponding stages of CNS development. The top series of boxes represents timing of the normal architectural patterning in the CNS. The bottom series of boxes indicates potential mechanisms of CNS injury surrounding operative intervention for HLHS (which could be extrapolated to other forms of CHD).

cardiopulmonary bypass (CPB) in the 1950s, surgical outcomes after complex cardiac surgery improved dramatically $(13,14)$. However, early experience using these techniques in children suggested an association with both early and late neurologic complications (15-21). Subsequent efforts to minimize the risk of ischemic brain injury during cardiac surgery have focused on the development of perioperative interventions that aim to optimize cerebral blood flow, minimize cerebral oxygen demand, and prevent neuronal cell damage. Examples of early neuroprotective strategies include the use of continuous low-flow CPB as an alternative to DHCA, the implementation of "temperature-corrected" (pH-stat) blood gas management strategies during patient cooling, and the development of various protocols for hemodilution, hypothermia, and rewarming surrounding CPB $(18,22-24)$. Although many of these interventions showed promising results in short-term follow-up, no single strategy has been shown to consistently and meaningfully improve long-term neurodevelopmental outcomes in patients undergoing early repair for CHD $(12,25)$.

Pharmacologic interventions. Pharmacologic approaches to neuroprotection have also historically identified the immediate perioperative period as an optimal point of intervention. Agents such as volatile anesthetics, methylprednisone, aprotinin, and allopurinol, among others, have been used to attenuate ischemic injury in infants undergoing cardiac surgery, based largely on experimental data that their effects may be neuroprotective (26-28). However, when applied clinically, none has been proven to reduce the risk of neurologic injury surrounding infant heart surgery. The perioperative administration of allopurinol (an inhibitor of free radical production) was not shown to significantly reduce the risk of death or neurologic injury surrounding surgical intervention (29), and the use of aprotinin (an antifibrinolytic) was completely halted after studies in adults showed an increased risk of renal failure and end-organ damage after CPB (30), although these results have not been duplicated in pediatric studies. Other commonly used agents—-such as isoflurane, midazolam, and methylpred- 
nisone-have yet to be studied in a systematic manner in patients with $\mathrm{CHD}$, and many questions remain regarding their safety and long-term effects on neurodevelopmental outcomes $(31,32)$.

\section{Unique Challenges to Neuroprotection in Infant Heart Surgery}

Practical limitations. Many factors contribute to slow progress in the development of effective interventions to improve neurocognitive outcomes in patients with CHD. One is that complex CHD, although a relatively common cause of childhood morbidity, remains a rare disease, affecting only 6 to 8 per 1000 live births (33). This limits our ability to design and successfully enroll patients in high-powered randomized trials, except in the largest institutions. Even multicenter trials are confounded by subtle differences in surgical technique and perioperative care. Furthermore, individual congenital heart defects demonstrate considerable variation in the unique physiologic and hemodynamic alterations that contribute to inherent neurologic risk, making results of even well-designed studies difficult to generalize across the spectrum of CHD.

Progress is further complicated by the fact that although gross neurologic impairments may be easily recognized in the immediate postoperative period, the full extent of adverse neuropsychological sequelae-including academic difficulties, behavior abnormalities, motor delays, executive planning, and inattention/hyperactivity $(4,16,34-39)$ — often do not become apparent until several years later when these children reach school age. This limits the timely assessment of any particular intervention.

Finally, although many of the neuroprotective strategies in current practice have been extrapolated from experimental or adult studies of cardiac surgery and CPB, clinical experience suggests that these models may not be adequate to reproduce the unique circumstances that contribute to neurologic injury in infants with CHD. Certainly, surrogate models have and will continue to provide great insight into the mechanisms that mediate neurologic injury during CPB. However, it is becoming increasingly clear that new approaches to neuroprotection will require a more precise understanding of patient-specific variables and the underlying mechanisms that contribute to neurologic injury in children with CHD-before, during, and after surgery.

Neurologic vulnerability in infants with $\mathrm{CHD}$. There now exists a growing body of evidence to suggest that many children with complex CHD suffer from abnormal or delayed brain development, potentially making them more vulnerable to neurologic insult suffered throughout the perinatal period $(3,40,41)$. Recent neuroimaging studies conducted in newborns with CHD (before surgical intervention) demonstrate abnormal findings similar to those seen in premature infants and those who have suffered hypoxic-ischemic injury $(3,12,40,41)$. Periventricular leukomalacia (PVL), the most common neuropathologic lesion identified in preterm neonates, is thought to result from enhanced vulnerability of premyelinating oligodendrocyte precursor cells to hypoxicischemic injury $(42,43)$. Damage to immature oligodendroglia associated with PVL impairs their ability to perform developmentally required functions in CNS patterning and neurotransmission, almost certainly contributing to long-term maladaptive consequences, which translate into the wide range of neurodevelopmental deficits that have been described both in survivors of premature birth and in those requiring early surgical intervention for CHD $(12,43)$. Recent studies report evidence of PVL on immediate postnatal imaging in up to $20 \%$ of full-term infants with CHD_increasing to more than $50 \%$ after surgery $(3,8,40)$ — suggesting a similarly increased vulnerability to white matter injury and raising questions of delayed brain maturation in these babies (42).

In addition to an underlying vulnerability to global hypoxicischemic insult, infants and children with CHD are at risk for focal neurologic injury from thromboembolism or air embolism, which can be related to the cardiac lesion itself or to the procedures required for repair or palliation. The incidence of perioperative stroke in pediatric patients undergoing open heart surgery has not yet been well defined. Risk factors such as type of lesion, age at surgery, perioperative hematocrit, and duration of CPB have been suggested, although none of these has been consistently shown to increase the risk of embolic events surrounding pediatric cardiac surgery $(40,44-47)$. One recent study of neonates and infants undergoing surgical repair for CHD demonstrated a 10\% prevalence of stroke, with as many as half of those events occurring preoperatively. This study also reported that the majority of lesions were identified only on early postoperative MRI with no clinical evidence of neurologic deficit, suggesting that focal neurologic insults are likely underdiagnosed in the infant population (45).

Furthermore, although it is generally accepted that the immature brain is more susceptible to neurologic injury caused by inflammation, oxidative stress, microemboli, and hemodynamic perturbations of cerebral blood flow associated with CPB (48-52), recent evidence suggests that additional mechanisms of neurologic injury exist, which may be unique to children with CHD. Subtle hemorrhagic events, as demonstrated by the presence of hemosiderin deposits on MRI, have recently been observed in a cohort of infants undergoing 2 -ventricle repair. These lesions were linked to lower Psychomotor Developmental Index scores at the age of $1 \mathrm{y}$. Importantly, such hemosiderin foci, or "microbleeds," were also associated with older age at surgery and were seen even in the absence of radiologic evidence of ischemic injury, suggesting a different pathogenesis for CNS damage than has previously been described (53).

Precarious physiology. Infants and children undergoing cardiac surgery remain vulnerable to neurologic injury throughout the postoperative period-and perhaps indefinitely. Low cardiac output syndrome (LCOS) refers to the predictable fall in cardiac output, which occurs $6-18 \mathrm{~h}$ after cardiac surgery $(54,55)$. Because of limited myocardial reserve, LCOS is common in pediatric patients, affecting up to $25 \%$ of neonates and young children undergoing surgical intervention for CHD $(54,55)$. Residual cardiac lesions, particularly in defects requiring staged palliation with a parallel circulation (such as hypoplastic left heart syndrome [HLHS]; Figs. 1 and 2), may further increase the risk of morbidity and 
mortality associated with LCOS (55-58). Hemodynamic instability associated with LCOS in the postoperative period leads to global hypoperfusion and can be associated with neurologic and other end-organ injury (55). Pharmacologic interventions to prevent LCOS have been associated with improved outcomes after surgery for CHD $(55,58)$. Although these agents might be considered an indirect approach to neuroprotection, their specific effects on long-term neurodevelopment have not been formally studied.

Finally, it must be remembered that many patients with CHD remain at risk for ongoing neurologic complications, well beyond the immediate perioperative period. Unfavorable hemodynamics, residual right-to-left intracardiac shunts, hypercoagulability, and arrhythmias can all contribute to increased risk for thromboembolic events and subsequent CNS injury, with certain lesions known to be at significant risk over a lifetime $(59,60)$. In addition, chronic cyanosis associated with many palliated lesions is most likely associated with poor long-term neurodevelopmental outcomes. In light of these complex issues, perhaps new strategies for neuroprotection should consider a multisystem approach.

\section{Ischemic Preconditioning: A Lesson in Neuroprotection}

Multisystem applications of ischemic preconditioning. An elegant illustration of the kind of multidisciplinary approach needed to support ongoing advances in neuroprotection surrounding pediatric cardiac surgery is that of ischemic preconditioning (IPC). IPC refers to a phenomenon in which prior exposure to a series of sublethal insults results in the upregulation of endogenous defense mechanisms, which then provide robust protection from subsequent lethal insults (61). IPC was first described in the mid-1980s in a model of myocardial infarction (62), and it has since been observed in extracardiac tissues including the brain, liver, and kidney. Subsequent investigations into the mechanisms that mediate the protection conferred by IPC in the heart and the brain have led to important advances in our understanding of numerous pathways that mediate cell fate in response to acute stress.

Signaling pathways in IPC: the heart and the brain are not the same. Both neurons and cardiomyocytes are highly metabolically active and have tremendously limited proliferative mechanisms. Therefore, in the context of providing neuroprotection during cardiac surgery, identification of the activator and effector molecules that are dually activated in the $\mathrm{CNS}$ and the heart is essential to provide therapies that target both the systems in a protective way. However, although neurons and cardiomyocytes share many characteristics, important differences in metabolic and cellular signaling pathways exist that are crucial to understanding the mechanisms by which each organ can elicit endogenous protection.

One of the most dramatic differences between cardiac and neuronal preconditioning is the lack of an early protective window for CNS models of ischemia. Unlike cardiomyocytes, which, on brief exposure to hypoxia and ischemia, induce a near immediate but short-lived protective period followed by a second protective period observed after hours and lasting for days, the CNS is only capable of inducing the late form of IPC (63-65).

The early cardiac IPC event has been associated with activation of the opioid and bradykinin receptor pathways (via PI3-kinase and ERK/Akt signaling), stimulation of the Gprotein coupled adenosine (A1) receptor, and the production of reactive oxygen species (ROS) in the mitochondria. Under the appropriate stimulus, all of these converge to activate protein kinase $\mathrm{C}$ (PKC), which acts as a final common pathway in the "trigger" phase of IPC (66). On reperfusion, PKC is primed to initiate a second round of activation of PI3kinase/Akt and MEK/ERK cell survival pathways to confer the protective effects of IPC (Fig. 3) (66,67).

The neural kinase pathways associated with CNS preconditioning protection are far less well appreciated. The convergence of stress signaling at the level of the mitochondria seems to be essential, and hallmark features of neuronal preconditioning include requirement for new protein synthesis, activation of heat shock proteins (HSPs), and opening of ATP-dependent potassium channels $(67,68)$. The redox sensitive pathways activated by preconditioning ischemia and reperfusion likely alter metabolic tone at the time of secondary stress, but the activation of this form of protection is much

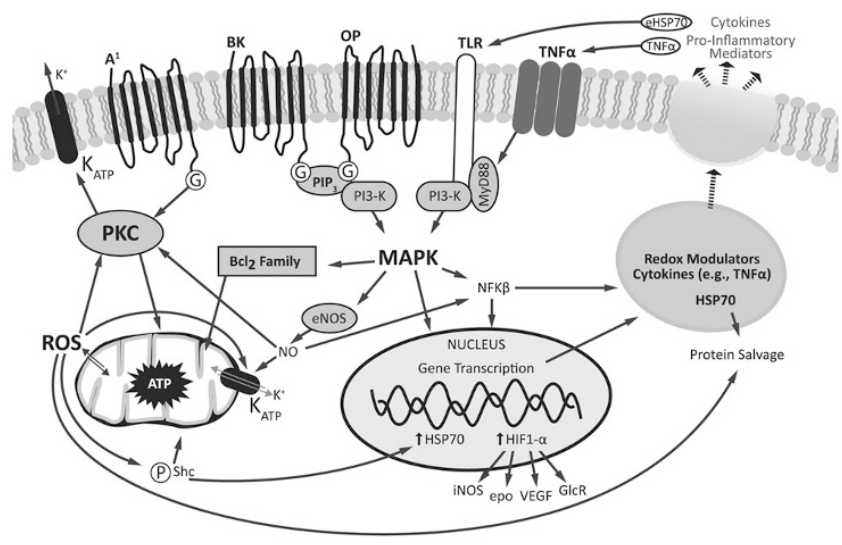

Figure 3. Signaling pathways involved in IPC. Focal ischemic insults result in initiation of cell stress pathways and rapid release of adenosine, acetylcholine, glutamate, and other neurotransmitters, which activate receptors including bradykinin (BK) and opioid (OP) receptors. These proteins are coupled to more general changes in kinase activation via phosphatidylinositol phosphatase-3 (PIP3), phosphoinositide 3-kinase (PI3-K), and mitogenactivated protein kinase (MAPK) signaling. The kinase-regulated signaling then signals secondary oxidative stress by stimulating NO production via endothelial NOS. Nitrosylative and oxidative stress activate mitochondrial ATP-dependent potassium channels $\left(\mathrm{K}_{\mathrm{ATP}}\right)$ and PKC. The oxidative stress signaling is initiated by loss of glucose and oxygen when cells experience hypoxia, which initiates mitochondrial dysfunction, ROS production, ATP depletion, and $\mathrm{p} 66^{\text {shc }}$ activation, which potentiates the activation of the mitochondrial $\mathrm{K}_{\mathrm{ATP}}$ channels. Cell stress signaling is dampened as oxygen is returned, and energetic and oxidative tone is restored. Additional levels of paracrine signaling are initiated by activation of innate immunity pathways via the redox-sensitive transcription factors including $\mathrm{NF} \kappa \mathrm{B}$ and hypoxia inducible factor 1 (HIF1). Activation of $\mathrm{NF} \kappa \mathrm{B}$ favors production of proteins, which participate in cellular protection such as HSP 70, cytokines, and modulators of oxidant stress. These molecules and endogenous proinflammatory molecules are thought to act on toll-like receptors (TLR) and TNF- $\alpha$ receptors to potentiate MAPK signaling pathways. Activation of HIF promotes expression of genes, which mediate cellular adaption to hypoxia (inducible NOS, erythropoietin [EPO], VEGF, glucose receptors [GlcR], among others). 
slower than cardiac preconditioning and can take hours to days to reveal itself.

Although activation of kinase pathways is necessary for IPC in both the heart and the brain, it is not sufficient for induction of protection. The protection observed in cardiac and neural cells hours after nonlethal priming stress requires new protein transcription, including up-regulation of HSPs and hypoxia inducible factor (HIF), among others (63). HSPs are cellular chaperones that act intracellularly to direct protein degradation or refolding in response to cell stress (61). Upregulation of these molecules in response to a preconditioning stress is required for protein salvage and enhanced cell survival in the face of subsequent otherwise lethal insults (69). HIF is a transcription factor that regulates the induction of hundreds of genes in response to cellular hypoxia, including those regulating endothelial NO production, erythropoietin synthesis, expression of multiple glucose transporters and glycolytic enzymes, and angiogenesis. HIF is known to be an essential mediator of preconditioning-induced cellular protection, presumably via stimulation of anaerobic glycolysis and preservation of mitochondrial function (65) (Fig. 3). The complexity of these adaptations is enormous, as each activated protein has a unique set of effector molecules, which regulate gene transcription, cell membrane channel properties, and metabolic function, the full effects of which we are only beginning to appreciate.

From laboratory to clinic: therapeutic implications of IPC. Continued advances in our understanding of the pathways that mediate IPC now offer a number of possible therapeutic targets that allow us to capitalize on the cell's endogenous protective mechanisms to limit injury from acute ischemic insult. A promising example of the therapeutic potential of IPC is the discovery of remote ischemic preconditioning (RIPC), a phenomenon whereby the application of a preconditioning stimulus at a remote site, such as the inflation of a blood pressure cuff around an arm or leg, confers IPC-like protection at a distant target (such as the heart and/or brain). First described in the mid-1990s in a model of myocardial infarction $(70,71)$, the protective effects of RIPC have been observed in various other tissues, including the brain.

The exact mechanisms through which RIPC exerts its distant effects remain unknown, but ongoing preclinical investigations suggest that multiple pathways may be involved. One proposed model of RIPC is that of a humoral pathway in which substances released at the site of a remote preconditioning stimulus circulate to their target organs to initiate cell-protective pathways. Convincing evidence in support of a humoral pathway was provided by an experimental model of heart transplantation in which RIPC applied to the recipient of a transplanted heart led to reduced myocardial infarct size in the donor heart (72). Another proposed mechanism is that of a neural pathway in which an endogenous substance released at the remote site of preconditioning activates afferent nerve fibers, which in turn stimulate IPC signaling pathways in the target organ. This model is supported by studies in which ganglion blockade or nerve dissection in the remote limb leads to complete block of IPC effect in the target organ, suggesting that intact neural pathways are required for RIPC-induced protection (73). An alternate, or perhaps complimentary, possibility is that of a systemic pathway in which RIPC induces organism-wide changes in gene expression, metabolism, and signaling, which serve to augment the local protective environment. In support of this, microarray analyses of preconditioned tissue have demonstrated up-regulation of multiple anti-inflammatory and antiapoptotic pathways after RIPC (74-76).

Although there is still much to be learned about the precise mechanisms that underlie the protection conferred by RIPC, several clinical applications of RIPC are currently being tested. These include therapeutic remote pre- and postconditioning after acute myocardial infarction, stroke, and even surrounding cardiac surgery. One randomized controlled study has shown evidence of myocardial protection (decreased troponin and decreased need for postoperative inotropic support) in children undergoing repair of CHD (77). Although there have been no studies examining the effects of RIPC on neurologic injury surrounding cardiac surgery, it certainly has exciting potential to be an inexpensive, well-tolerated neuroprotective therapy for patients undergoing $\mathrm{CPB}$.

\section{The Future of Neuroprotection in Infant Heart Surgery}

Despite limited progress in the improvement of neurodevelopmental outcomes for children undergoing repair of CHD over the last $20 \mathrm{y}$, remarkable advances in molecular science and technology have provided us with a better understanding of the mechanisms that underlie neuropathology in a variety of models, thus offering new and innovative approaches to the diagnosis and prevention of neurologic injury in patients with CHD (Table 1).

Preoperative considerations. Early and accurate prenatal diagnosis of complex CHD by fetal echocardiography now allows for planned delivery in an advanced nursery setting where prompt initiation of medical therapy can minimize the risk for early hemodynamic compromise, potentially contributing to improved neurologic outcomes in some groups $(78,79)$. In select cases, prenatal diagnosis also offers the opportunity for highly specialized fetal cardiac intervention, which - by optimizing fetal hemodynamics - has the potential to not only improve cardiovascular outcomes but also to restore physiologic cerebral circulation, theoretically promoting normal CNS development. Although one recent study showed no significant change in cerebral blood flow after fetal intervention for aortic stenosis (80), continued modification and ongoing study of these relatively new techniques will be required to assess any impact on long-term neurodevelopmental outcomes.

Other antenatal therapies that may be of benefit in cases of prenatally diagnosed CHD include those currently being developed to prevent PVL and associated long-term brain injury in premature infants, such as maternal administration of free radical scavengers such as vitamin $\mathrm{E}$ and anti-inflammatory and anticytokine agents (43). Although future study is needed, continued advances in the understanding of the common pathways that participate in the development of PVL, such as ischemia-reperfusion and free-radical injury, can propel the 
Table 1. Multidisciplinary approaches to diagnosis, monitoring, and prevention of neurologic injury throughout the perioperative period

\begin{tabular}{|c|c|c|c|}
\hline & Preoperative & Intraoperative & Postoperative \\
\hline \multirow[t]{4}{*}{ Tools for diagnosis/monitoring } & Imaging (ultrasound, MRI) & NIRS & Imaging (ultrasound, MRI) \\
\hline & EEG, ERP & Biomarkers & NIRS \\
\hline & Genetic analysis, risk stratification & & Biomarkers \\
\hline & Biomarkers & & EEG, ERP \\
\hline \multirow[t]{5}{*}{ Strategies for neuroprotection } & $\begin{array}{l}\text { Fetal intervention for CHD } \\
\text { (improved cerebral blood flow) }\end{array}$ & $\begin{array}{l}\text { Modified perfusion techniques (RLFP, } \\
\text { new circuits, etc.) }\end{array}$ & Postconditioning therapies \\
\hline & Prenatal therapy for PVL & Modified cooling/rewarming protocols & $\begin{array}{l}\text { Afterload reduction (avoid } \\
\text { LCOS) }\end{array}$ \\
\hline & & Preconditioning therapies & \\
\hline & & RIPC & \\
\hline & & Pharmacologic & \\
\hline
\end{tabular}

ERP, evoked response potential; NIRS, near-infrared-spectroscopy; CHD, congenital heart disease; LCOS, low cardiac output syndrome; PVL, per ventricular leukomalacia; RIPC, remote ischemic preconditioning.

development of neuroprotection strategies, which may be effective in both of these vulnerable populations.

Finally, improved understanding of the genetic and molecular basis of CHD over recent years has led to the identification of multiple genes that participate in the development of a variety of congenital heart lesions, and the genetic heritability of some forms of CHD has now been well described (81). Similarly, genetic influences on abnormal neurologic development in patients with CHD are also being explored. Gaynor et al. $(82,83)$ have described that polymorphisms in the Apo-E allele may correlate with poor neurologic outcome. As knowledge in this area continues to grow, genetic factors will become extremely important as predictors of neurologic risk, and a more patient-specific approach to risk-stratification and intervention will be required.

Intraoperative considerations. Intraoperative management strategies remain important modifiable factors, which will continue to evolve in attempts to improve neurodevelopmental outcomes. Emerging modifications in surgical technologies, including the development of hybrid strategies in the repair of HLHS and the use of regional low-flow cerebral perfusion (RLFP) (84), and more advanced monitoring of cerebral oxygen saturation using near-infrared-spectroscopy (NIRS), are currently being studied; however, long-term outcomes have not yet been determined (31).

In addition, modified perfusion strategies such as the use of coated CPB circuitry and leukocyte filtration strategies (85), modified ultrafiltration (86), miniaturized circuits using reduced or asanguinous blood prime (87-89), and newer normothermic and normoxic perfusion protocols $(90,91)$ are currently in varying stages of development and testing, with long-term results still pending. Although unique pediatric issues remain, close collaboration with our adult and basic science counterparts should allow better understanding of CPB-related complications, which will help target pathways for prevention and treatment of multiorgan dysfunction in both adults and children requiring cardiac surgery.

The operative period also remains an attractive target for neuroprotective pharmacotherapy. Further study of currently used perioperative medications including steroids and anesthetic agents is essential and ongoing. Moreover, as the pathways which mediate the protective effects of IPC are further elucidated, clinicians and scientists are seeking to capitalize on the planned nature of the ischemic injury caused by cardiac surgery by developing therapies aimed at enhancing endogenous cellular protective mechanisms. One such novel therapy was recently described using siRNA to inhibit translation of the prolyl-hydroxylase (PHD) enzymes, which act to target HIF- $1 \alpha$ (a subunit of the HIF complex) for proteasomal degradation under normal conditions. In a murine model of myocardial infarction, treatment with these siRNA PHD inhibitors allowed for the activation of HIF and subsequent protection from ischemia, similar to that seen in preconditioned cells (92). Other studies have shown that the molecular chaperone HSP70, which is essential for intracellular preconditioning protection, may also exert neuroprotective effects when released extracellularly, and that exogenous administration of HSP70 may induce preconditioning-like neuroprotection. Certainly, clinical applications of these and other preconditioning therapies, such as RIPC, are intriguing and require further collaborative study.

Postoperative considerations. An important challenge to the clinical management of potential adverse neurologic outcomes in infants with CHD is lack of tools that can aid in the timely assessment of neurologic deficits. This would be helped by the development of an accurate and specific biomarker of neurologic injury. Candidate biomarkers such as HSPs, IL-6, C-reactive protein, S-100b, neuron specific enolase (50), serum calcium (93), and activin A (94) are being investigated in studies of CPB and multiple other models of neurologic injury, and we await studies assessing the value of these markers as indices of long-term outcomes.

We are keenly interested in developing peripheral biomarkers of CNS stress, which may be useful in a variety of clinical settings. Isoprostanes (IsoPs), prostaglandin-like molecules formed in vivo via the free radical-mediated oxidation of arachidonic acid, have been demonstrated to be formed in increased amounts in the brains of patients with various neurodegenerative diseases $(95,96)$. Widely considered the "gold standard" for quantification of oxidative stress, F2-IsoP formation is currently being studied in a variety of patient populations, but there are limited published data in neonatal models of hypoxia or in children with CHD. Similar free radical-mediated oxidation of docosahexaenoic acid (DHA) the predominant fatty acid found in neurons of normal human brain-leads to the formation of neuroprostanes (NPs), which 
may serve as a more sensitive biomarker of oxidative injury specific to the brain $(97,98)$. Studies of IsoP and NP formation surrounding pediatric cardiac surgery are underway and may provide insights into the timing and extent of oxidative injury during and after surgical intervention for CHD.

Overcoming obstacles: a combined effort. There remain a number of clinical and practical issues that contribute to the slow progress toward achieving measurable improvements in neurodevelopmental outcomes in patients with CHD. Faced with small sample sizes, time constraints, resource limitations, and the very important logistical and ethical considerations of conducting research in this vulnerable population, individual institutions are often unable to conduct the kind of highimpact studies needed to answer important questions regarding the safety and efficacy of new and emerging neuroprotective strategies. However, the recent and ongoing development of several multi-institutional collaborations, such as the Pediatric Heart Network (PHN) and the Joint Council on Congenital Heart Disease (JCCHD), provide promise for future implementation of large-scale trials and quality-improvement efforts. Moreover, ongoing multidisciplinary collaborations between pediatric and adult cardiologists, cardiac surgeons, neonatologists, neurologists, developmental specialists, and basic scientists will be essential to our continued progress, as contributions from each area of expertise can be integrated to help answer mutual questions with applications across disciplines.

\section{CONCLUSIONS}

Adverse neurodevelopmental outcomes after early surgical repair of CHD represent a significant cause of morbidity in a growing number of survivors. Historical approaches toward modification of intraoperative management strategies have not been shown to impact long-term outcomes. Although children with $\mathrm{CHD}$ remain a specialized population with a unique set of risk factors, investigations in other models of neurologic injury have led to dramatic advances in our understanding of the intricate processes that direct cellular injury and adaption in response to stress, providing a variety of new potential targets for the prevention and treatment of neurologic injury. As our understanding of the genetic and molecular basis of CHD expands, patient-specific variables will become central to the formulation of unique strategies for risk stratification and management. Although challenges remain, it is clear that through continued study and collaboration, there exists tremendous opportunity for the development of diagnostic and therapeutic interventions that can serve to limit neurologic sequelae and ultimately improve outcomes for patients with CHD.

Acknowledgments. We thank Drs. Judy Aschner, Gregg Stanwood, Ann Kavanaugh-McHugh, and Jonathon Soslow for their advice and editorial assistance. Graphic support was provided by Kylie Beck at the Vanderbilt Kennedy Center.

\section{REFERENCES}

1. Khairy P, Poirier N, Mercier LA 2007 Univentricular heart. Circulation 115:800812
2. Markowitz SD, Ichord RN, Wernovsky G, Gaynor JW, Nicolson SC 2007 Surrogate markers for neurological outcome in children after deep hypothermic circulatory arrest. Semin Cardiothorac Vasc Anesth 11:59-65

3. Miller SP, McQuillen PS, Hamrick S, Xu D, Glidden DV, Charlton N, Karl T, Azakie A, Ferriero DM, Barkovich AJ, Vigneron DB 2007 Abnormal brain development in newborns with congenital heart disease. N Engl J Med 357:1928-1938

4. Ballweg JA, Wernovsky G, Gaynor JW 2007 Neurodevelopmental outcomes following congenital heart surgery. Pediatr Cardiol 28:126-133

5. Dominguez TE, Wernovsky G, Gaynor JW 2007 Cause and prevention of central nervous system injury in neonates undergoing cardiac surgery. Semin Thorac Cardiovasc Surg 19:269-277

6. Dittrich H, Buhrer C, Grimmer I, Dittrich S, Abdul-Khaliq H, Lange PE 2003 Neurodevelopment at 1 year of age in infants with congenital heart disease. Heart 89:436-441

7. Majnemer A, Limperopoulos C, Shevell MI, Rohlicek C, Rosenblatt B, Tchervenkov C 2009 A new look at outcomes of infants with congenital heart disease. Pediatr Neurol 40:197-204

8. Galli KK, Zimmerman RA, Jarvik GP, Wernovsky G, Kuypers MK, Clancy RR, Montenegro LM, Mahle WT, Newman MF, Saunders AM, Nicolson SC, Spray TL, Gaynor JW 2004 Periventricular leukomalacia is common after neonatal cardiac surgery. J Thorac Cardiovasc Surg 127:692-704

9. Limperopoulos C, Majnemer A, Shevell MI, Rohlicek C, Rosenblatt B, Tchervenkov C, Darwish HZ 2002 Predictors of developmental disabilities after open heart surgery in young children with congenital heart defects. J Pediatr 141:51-58

10. Limperopoulos C, Majnemer A, Shevell MI, Rosenblatt B, Rohlicek C, Tchervenkov C 2000 Neurodevelopmental status of newborns and infants with congenital heart defects before and after open heart surgery. J Pediatr 137:638-645

11. Trittenwein G, Nardi A, Pansi H, Golej J, Burda G, Hermon M, Boigner H, Wollenek G 2003 Early postoperative prediction of cerebral damage after pediatric cardiac surgery. Ann Thorac Surg 76:576-580

12. Clancy RR 2008 Neuroprotection in infant heart surgery. Clin Perinatol 35:809821 viii

13. Amir G, Ramamoorthy C, Riemer RK, Reddy VM, Hanley FL 2005 Neonatal brain protection and deep hypothermic circulatory arrest: pathophysiology of ischemic neuronal injury and protective strategies. Ann Thorac Surg 80:1955-1964

14. Stoney WS 2009 Evolution of cardiopulmonary bypass. Circulation 119:2844-2853

15. Bellinger DC, Jonas RA, Rappaport LA, Wypij D, Wernovsky G, Kuban KC, Barnes PD, Holmes GL, Hickey PR, Strand RD, Walsh AZ, Helmers SL, Constantinou JE, Carrazana EJ, Mayer JE, Hanley FL, Castaneda AR, Ware JH, Newburger JW 1995 Developmental and neurologic status of children after heart surgery with hypothermic circulatory arrest or low-flow cardiopulmonary bypass. N Engl J Med 332:549555

16. Bellinger DC, Wypij D, duDuplessis AJ, Rappaport LA, Jonas RA, Wernovsky G, Newburger JW 2003 Neurodevelopmental status at eight years in children with dextro-transposition of the great arteries: the Boston Circulatory Arrest Trial J Thorac Cardiovasc Surg 126:1385-1396

17. Bellinger DC, Wypij D, Kuban KC, Rappaport LA, Hickey PR, Wernovsky G, Jonas RA, Newburger JW 1999 Developmental and neurological status of children at 4 years of age after heart surgery with hypothermic circulatory arrest or low-flow cardiopulmonary bypass. Circulation 100:526-532

18. Newburger JW, Jonas RA, Wernovsky G, Wypij D, Hickey PR, Kuban KC, Farrell DM, Holmes GL, Helmers SL, Constantinou J, Carrazana E, Barlow JK, Walsh AZ, Lucius KC, Share JC, Wessel DL, Hanley FL, Mayer JE, Castaneda AR, Ware JH 1993 A comparison of the perioperative neurologic effects of hypothermic circulatory arrest versus low-flow cardiopulmonary bypass in infant heart surgery. $\mathrm{N}$ Engl J Med 329:1057-1064

19. Wypij D, Newburger JW, Rappaport LA, duPlessis AJ, Jonas RA, Wernovsky G, Lin M, Bellinger DC 2003 The effect of duration of deep hypothermic circulatory arrest in infant heart surgery on late neurodevelopment: the Boston Circulatory Arrest Trial. J Thorac Cardiovasc Surg 126:1397-1403

20. Brunberg JA, Doty DB, Reilly EL 1974 Choreoathetosis in infants following cardiac surgery with deep hypothermia and circulatory arrest. J Pediatr 84:232-235

21. du Plessis AJ, Bellinger DC, Gauvreau K, Plumb C, Newburger JW, Jonas RA, Wessel DL 2002 Neurologic outcome of choreoathetoid encephalopathy after cardiac surgery. Pediatr Neurol 27:9-17

22. Bellinger DC, Wypij D, du Plessis AJ, Rappaport LA, Riviello J, Jonas RA, Newburger JW 2001 Developmental and neurologic effects of alpha-stat versus $\mathrm{pH}$-stat strategies for deep hypothermic cardiopulmonary bypass in infants. J Thorac Cardiovasc Surg 121:374-383

23. Jonas RA, Wypij D, Roth SJ, Bellinger DC, Visconti KJ, du Plessis AJ, Goodkin H, Laussen PC, Farrell DM, Bartlett J, McGrath E, Rappaport LJ, Bacha EA, Forbess JM, del Nido PJ, Mayer JE Jr, Newburger JW 2003 The influence of hemodilution on outcome after hypothermic cardiopulmonary bypass: results of a randomized trial in infants. J Thorac Cardiovasc Surg 126:1765-1774

24. Newburger JW, Jonas RA, Soul J, Kussman BD, Bellinger DC, Laussen PC, Robertson R, Mayer JE Jr, del Nido PJ, Bacha EA, Forbess JM, Pigula F, Roth SJ, Visconti KJ, du Plessis AJ, Farrell DM, McGrath E, Rappaport LA, Wypij D 2008 Randomized trial of hematocrit $25 \%$ versus $35 \%$ during hypothermic cardiopulmonary bypass in infant heart surgery. J Thorac Cardiovasc Surg 135:347-354, 354.e1-354.e4

25. Wernovsky G, Shillingford AJ, Gaynor JW 2005 Central nervous system outcomes in children with complex congenital heart disease. Curr Opin Cardiol 20:94-99

26. Langley SM, Chai PJ, Jaggers JJ, Ungerleider RM 2000 Preoperative high dose methylprednisolone attenuates the cerebral response to deep hypothermic circulatory arrest. Eur J Cardiothorac Surg 17:279-286 
27. Lodge AJ, Chai PJ, Daggett CW, Ungerleider RM, Jaggers J 1999 Methylprednisolone reduces the inflammatory response to cardiopulmonary bypass in neonatal piglets: timing of dose is important. J Thorac Cardiovasc Surg 117:515-522

28. Kurth CD, Priestley M, Watzman HM, McCann J, Golden J 2001 Desflurane confers neurologic protection for deep hypothermic circulatory arrest in newborn pigs. Anesthesiology 95:959-964

29. Clancy RR, McGaurn SA, Goin JE, Hirtz DG, Norwood WI, Gaynor JW, Jacobs ML, Wernovsky G, Mahle WT, Murphy JD, Nicolson SC, Steven JM, Spray TL 2001 Allopurinol neurocardiac protection trial in infants undergoing heart surgery using deep hypothermic circulatory arrest. Pediatrics 108:61-70

30. Mangano DT, Tudor IC, Dietzel C 2006 The risk associated with aprotinin in cardiac surgery. N Engl J Med 354:353-365

31. Massaro AN, El-Dib M, Glass P, Aly H 2008 Factors associated with adverse neurodevelopmental outcomes in infants with congenital heart disease. Brain Dev 30:437-446

32. Istaphanous GK, Loepke AW 2009 General anesthetics and the developing brain Curr Opin Anaesthesiol 22:368-373

33. Hoffman JI, Kaplan S 2002 The incidence of congenital heart disease. J Am Coll Cardiol 39:1890-1900

34. Forbess JM, Visconti KJ, Hancock-Friesen C, Howe RC, Bellinger DC, Jonas RA 2002 Neurodevelopmental outcome after congenital heart surgery: results from an institutional registry. Circulation 106:I95-I102

35. Limperopoulos C, Majnemer A, Shevell MI, Rosenblatt B, Rohlicek C, Tchervenkov C, Darwish HZ 2001 Functional limitations in young children with congenital heart defects after cardiac surgery. Pediatrics 108:1325-1331

36. Majnemer A, Limperopoulos C, Shevell M, Rosenblatt B, Rohlicek C, Tchervenkov C 2006 Long-term neuromotor outcome at school entry of infants with congenital heart defects requiring open-heart surgery. J Pediatr 148:72-77

37. Miatton M, De Wolf D, Francois K, Thiery E, Vingerhoets G 2007 Neuropsychological performance in school-aged children with surgically corrected congenital heart disease. J Pediatr 151:73-78, 78.e71

38. Shillingford AJ, Glanzman MM, Ittenbach RF, Clancy RR, Gaynor JW, Wernovsky G 2008 Inattention, hyperactivity, and school performance in a population of school-age children with complex congenital heart disease. Pediatrics 121:e759e767

39. Wernovsky G 2006 Current insights regarding neurological and developmental abnormalities in children and young adults with complex congenital cardiac disease. Cardiol Young 16:92-104

40. Mahle WT, Tavani F, Zimmerman RA, Nicolson SC, Galli KK, Gaynor JW, Clancy RR, Montenegro LM, Spray TL, Chiavacci RM, Wernovsky G, Kurth CD 2002 An MRI study of neurological injury before and after congenital heart surgery. Circulation 106:I109-I114

41. Miller G, Vogel H 1999 Structural evidence of injury or malformation in the brains of children with congenital heart disease. Semin Pediatr Neurol 6:20-26

42. Licht DJ, Shera DM, Clancy RR, Wernovsky G, Montenegro LM, Nicolson SC, Zimmerman RA, Spray TL, Gaynor JW, Vossough A 2009 Brain maturation is delayed in infants with complex congenital heart defects. J Thorac Cardiovasc Surg 137:529-537

43. Volpe JJ 2001 Neurobiology of periventricular leukomalacia in the premature infant. Pediatr Res 50:553-562

44. Beca J, Gunn J, Coleman L, Hope A, Whelan LC, Gentles T, Inder T, Hunt R, Shekerdemian L 2009 Pre-operative brain injury in newborn infants with transposition of the great arteries occurs at rates similar to other complex congenital heart disease and is not related to balloon atrial septostomy. J Am Coll Cardiol 53:18071811

45. Chen J, Zimmerman RA, Jarvik GP, Nord AS, Clancy RR, Wernovsky G, Montenegro LM, Hartman DM, Nicolson SC, Spray TL, Gaynor JW, Ichord R 2009 Perioperative stroke in infants undergoing open heart operations for congenital heart disease. Ann Thorac Surg 88:823-829

46. Domi T, Edgell DS, McCrindle BW, Williams WG, Chan AK, MacGregor DL, Kirton A, deVeber GA 2008 Frequency, predictors, and neurologic outcomes of vaso-occlusive strokes associated with cardiac surgery in children. Pediatrics 122:1292-1298

47. Miller G, Mamourian AC, Tesman JR, Baylen BG, Myers JL 1994 Long-term MRI changes in brain after pediatric open heart surgery. J Child Neurol 9:390-397

48. Cavalca V, Sisillo E, Veglia F, Tremoli E, Cighetti G, Salvi L, Sola A, Mussoni L, Biglioli P, Folco G, Sala A, Parolari A 2006 Isoprostanes and oxidative stress in off-pump and on-pump coronary bypass surgery. Ann Thorac Surg 81:562-567

49. Dybdahl B, Wahba A, Lien E, Flo TH, Waage A, Qureshi N, Sellevold OF, Espevik T, Sundan A 2002 Inflammatory response after open heart surgery: release of heat-shock protein 70 and signaling through toll-like receptor-4. Circulation 105:685-690

50. Ramlawi B, Rudolph JL, Mieno S, Khabbaz K, Sodha NR, Boodhwani M, Levkoff SE, Marcantonio ER, Sellke FW 2006 Serologic markers of brain injury and cognitive function after cardiopulmonary bypass. Ann Surg 244:593-601

51. Ulus AT, Aksoyek A, Ozkan M, Katircioglu SF, Basu S 2003 Cardiopulmonary bypass as a cause of free radical-induced oxidative stress and enhanced blood-borne isoprostanes in humans. Free Radic Biol Med 34:911-917

52. Sherlock RL, McQuillen PS, Miller SP 2009 Preventing brain injury in newborns with congenital heart disease: brain imaging and innovative trial designs. Stroke 40:327-332

53. Soul JS, Robertson RL, Wypij D, Bellinger DC, Visconti KJ, du Plessis AJ, Kussman BD, Scoppettuolo LA, Pigula F, Jonas RA, Newburger JW 2009 Subtle hemorrhagic brain injury is associated with neurodevelopmental impairment in infants with repaired congenital heart disease. J Thorac Cardiovasc Surg 138:374381
54. Hoffman TM, Wernovsky G, Atz AM, Bailey JM, Akbary A, Kocsis JF, Nelson DP, Chang AC, Kulik TJ, Spray TL, Wessel DL 2002 Prophylactic Intravenous Use of Milrinone After Cardiac Operation in Pediatrics (PRIMACORP) study. Prophylactic intravenous use of milrinone after cardiac operation in pediatrics. Am Heart $\mathrm{J}$ $143: 15-21$

55. Hoffman TM, Wernovsky G, Atz AM, Kulik TJ, Nelson DP, Chang AC, Bailey JM, Akbary A, Kocsis JF, Kaczmarek R, Spray TL, Wessel DL 2003 Efficacy and safety of milrinone in preventing low cardiac output syndrome in infants and children after corrective surgery for congenital heart disease. Circulation 107:996-1002

56. Guzzetta NA 2007 Phenoxybenzamine in the treatment of hypoplastic left hear syndrome: a core review. Anesth Analg 105:312-315

57. Hoffman GM, Tweddell JS, Ghanayem NS, Mussatto KA, Stuth EA, Jaquis RD, Berger S 2004 Alteration of the critical arteriovenous oxygen saturation relationship by sustained afterload reduction after the Norwood procedure. J Thorac Cardiovasc Surg 127:738-745

58. Tweddell JS, Hoffman GM, Fedderly RT, Berger S, Thomas JP Jr, Ghanayem NS, Kessel MW, Litwin SB 1999 Phenoxybenzamine improves systemic oxygen delivery after the Norwood procedure. Ann Thorac Surg 67:161-167; discussion 167-168

59. du Plessis AJ, Chang AC, Wessel DL, Lock JE, Wernovsky G, Newburger JW, Mayer JE Jr 1995 Cerebrovascular accidents following the Fontan operation. Pediatr Neurol 12:230-236

60. Rosenthal DN, Friedman AH, Kleinman CS, Kopf GS, Rosenfeld LE, Hellenbrand WE 1995 Thromboembolic complications after Fontan operations. Circulation 92:II287-II293

61. O'Duffy AE, Bordelon YM, McLaughlin B 2007 Killer proteases and little strokeshow the things that do not kill you make you stronger. J Cereb Blood Flow Metab 27:655-668

62. Murry CE, Jennings RB, Reimer KA 1986 Preconditioning with ischemia: a delay of lethal cell injury in ischemic myocardium. Circulation 74:1124-1136

63. Barone FC 2005 Endogenous brain protection-models, gene expression, and mechanisms. In: Read SJ, Virley D (eds) Stroke Genomics: Methods and Reviews. Humana Press, Totowa, pp 105-184

64. Dave KR, DeFazio RA, Raval AP, Torraco A, Saul I, Barrientos A, Perez-Pinzon MA 2008 Ischemic preconditioning targets the respiration of synaptic mitochondria via Protein Kinase C. J Neurosci 28:4172-4182

65. Yenari M, Kitagawa K, Lyden P, Perez-Pinzon M 2008 Metabolic downregulation: a key to successful neuroprotection? Stroke 39:2910-2917

66. Downey JM, Davis AM, Cohen MV 2007 Signaling pathways in ischemic preconditioning. Heart Fail Rev 12:181-188

67. Gidday JM 2006 Cerebral preconditioning and ischaemic tolerance. Nat Rev Neurosci 7:437-448

68. Obrenovitch TP 2008 Molecular physiology of preconditioning-induced brain tolerance to ischemia. Physiol Rev 88:211-247

69. McLaughlin B, Hartnett KA, Erhardt JA, Legos JJ, White RF, Barone FC, Aizenman E 2003 Caspase 3 activation is essential for neuroprotection in preconditioning. Proc Natl Acad Sci USA 100:715-720

70. Gho BC, Schoemaker RG, van den Doel MA, Duncker DJ, Verdouw PD 1996 Myocardial protection by brief ischemia in noncardiac tissue. Circulation 94:21932200

71. Przyklenk K, Bauer B, Ovize M, Kloner RA, Whittaker P 1993 Regional ischemic 'preconditioning' protects remote virgin myocardium from subsequent sustained coronary occlusion. Circulation 87:893-899

72. Konstantinov IE, Li J, Cheung MM, Shimizu M, Stokoe J, Kharbanda RK, Redington AN 2005 Remote ischemic preconditioning of the recipient reduces myocardial ischemia-reperfusion injury of the denervated donor heart via a Katp channeldependent mechanism. Transplantation 79:1691-1695

73. Dong JH, Liu YX, Ji ES, He RR 2004 [Limb ischemic preconditioning reduces infarct size following myocardial ischemia-reperfusion in rats]. Sheng Li Xue Bao $56: 41-46$

74. Dhodda VK, Sailor KA, Bowen KK, Vemuganti R 2004 Putative endogenous mediators of preconditioning-induced ischemic tolerance in rat brain identified by genomic and proteomic analysis. J Neurochem 89:73-89

75. Stenzel-Poore MP, Stevens SL, Simon RP 2004 Genomics of preconditioning. Stroke 35:2683-2686

76. Hausenloy DJ, Yellon DM 2008 Remote ischaemic preconditioning: underlying mechanisms and clinical application. Cardiovasc Res 79:377-386

77. Cheung MM, Kharbanda RK, Konstantinov IE, Shimizu M, Frndova H, Li J, Holtby HM, Cox PN, Smallhorn JF, Van Arsdell GS, Redington AN 2006 Randomized controlled trial of the effects of remote ischemic preconditioning on children undergoing cardiac surgery: first clinical application in humans. J Am Coll Cardiol 47:2277-2282

78. Mahle WT, Clancy RR, McGaurn SP, Goin JE, Clark BJ 2001 Impact of prenatal diagnosis on survival and early neurologic morbidity in neonates with the hypoplastic left heart syndrome. Pediatrics 107:1277-1282

79. Eapen RS, Rowland DG, Franklin WH 1998 Effect of prenatal diagnosis of critical left heart obstruction on perinatal morbidity and mortality. Am J Perinatol 15:237242

80. McElhinney DB, Benson CB, Brown DW, Wilkins-Haug LE, Marshall AC, Zaccagnini L, Tworetzky W 2010 Cerebral blood flow characteristics and biometry in fetuses undergoing prenatal intervention for aortic stenosis with evolving hypoplastic left heart syndrome. Ultrasound Med Biol 36:29-37

81. Sander TL, Klinkner DB, Tomita-Mitchell A, Mitchell ME 2006 Molecular and cellular basis of congenital heart disease. Pediatr Clin North Am 53:989-1009

82. Gaynor JW, Gerdes M, Zackai EH, Bernbaum J, Wernovsky G, Clancy RR, Newman MF, Saunders AM, Heagerty PJ, D'Agostino JA, McDonald-McGinn D, Nicolson SC, Spray TL, Jarvik GP 2003 Apolipoprotein E genotype and neurode- 
velopmental sequelae of infant cardiac surgery. J Thorac Cardiovasc Surg 126:1736-1745

83. Gaynor JW, Wernovsky G, Jarvik GP, Bernbaum J, Gerdes M, Zackai E, Nord AS, Clancy RR, Nicolson SC, Spray TL 2007 Patient characteristics are important determinants of neurodevelopmental outcome at one year of age after neonatal and infant cardiac surgery. J Thorac Cardiovasc Surg 133:1344-1353, 1353.e1-1353.e3

84. Chock VY, Amir G, Davis CR, Ramamoorthy C, Riemer RK, Ray D, Giffard RG, Reddy VM 2006 Antegrade cerebral perfusion reduces apoptotic neuronal injury in a neonatal piglet model of cardiopulmonary bypass. J Thorac Cardiovasc Surg 131:659-665

85. Warren O, Alexiou C, Massey R, Leff D, Purkayastha S, Kinross J, Darzi A, Athanasiou T 2007 The effects of various leukocyte filtration strategies in cardiac surgery. Eur J Cardiothorac Surg 31:665-676

86. Gaynor JW 2003 The effect of modified ultrafiltration on the postoperative course in patients with congenital heart disease. Semin Thorac Cardiovasc Surg Pediatr Card Surg Annu 6:128-139

87. Hickey E, Karamlou T, You J, Ungerleider RM 2006 Effects of circuit miniaturization in reducing inflammatory response to infant cardiopulmonary bypass by elimination of allogeneic blood products. Ann Thorac Surg 81:S2367-S2372

88. Hickey E, Karamlou T, You XM, Komanapalli C, Person T, Wehrley K, Ungerleider R 2007 The use of a miniaturized circuit and bloodless prime to avoid cerebral no-reflow after neonatal cardiopulmonary bypass. Ann Thorac Surg 83:895-901

89. Karamlou T, Schultz JM, Silliman C, Sandquist C, You J, Shen I, Ungerleider RM 2005 Using a miniaturized circuit and an asanguineous prime to reduce neutrophilmediated organ dysfunction following infant cardiopulmonary bypass. Ann Thorac Surg 80:6-14
90. Caputo M, Mokhtari A, Rogers CA, Panayiotou N, Chen Q, Ghorbel MT, Angelini GD, Parry AJ 2009 The effects of normoxic versus hyperoxic cardiopulmonary bypass on oxidative stress and inflammatory response in cyanotic pediatric patients undergoing open cardiac surgery: a randomized controlled trial. J Thorac Cardiovasc Surg 138:206-214

91. Durandy YD, Younes M, Mahut B 2008 Pediatric warm open heart surgery and prolonged cross-clamp time. Ann Thorac Surg 86:1941-1947

92. Eckle T, Kohler D, Lehmann R, El Kasmi K, Eltzschig HK 2008 Hypoxia-inducible factor-1 is central to cardioprotection: a new paradigm for ischemic preconditioning. Circulation 118:166-175

93. Ovbiagele B, Starkman S, Teal P, Lyden P, Kaste M, Davis SM, Hacke W, Fierus M, Saver JL 2008 Serum calcium as prognosticator in ischemic stroke. Stroke 39:2231-2236

94. Florio P, Abella RF, de la Torre T, Giamberti A, Luisi S, Butera G, Cazzaniga A, Frigiola A, Petraglia F, Gazzolo D 2007 Perioperative activin A concentrations as a predictive marker of neurologic abnormalities in children after open heart surgery. Clin Chem 53:982-985

95. Montine KS, Quinn JF, Zhang J, Fessel JP, Roberts LJ II, Morrow JD, Montine TJ 2004 Isoprostanes and related products of lipid peroxidation in neurodegenerative diseases. Chem Phys Lipids 128:117-124

96. Montine TJ, Neely MD, Quinn JF, Beal MF, Markesbery WR, Roberts LJ, Morrow JD 2002 Lipid peroxidation in aging brain and Alzheimer's disease. Free Radic Biol Med 33:620-626

97. Arneson KO, Roberts LJ II 2007 Measurement of products of docosahexaenoic acid peroxidation, neuroprostanes, and neurofurans. Methods Enzymol 433:127-143

98. Roberts LJ II, Fessel JP 2004 The biochemistry of the isoprostane, neuroprostane, and isofuran pathways of lipid peroxidation. Chem Phys Lipids 128:173-186 